CANADIAN JOURNAL OF PHILOSOPHY

Volume 43 Numbers 5-6 October-December 2013

SPECIAL ISSUE: Essays on the Nature of Propositions

GUEST EDITORS: David Hunter and Gurpreet Rattan

\title{
CONTENTS
}

Introduction

David Hunter and Gurpreet Rattan

On Act- and Language-Based Conceptions of Propositions

Two aspects of propositional unity

Gary Ostertag

An empirically-informed cognitive theory of propositions

Berit Brogaard

What are the primary bearers of truth?

Peter Hanks

Not the optimistic type

Ben Caplan, Chris Tillman, Brian McLean and Adam Murray

Why it isn't syntax that unifies the proposition

Logan Fletcher

Why we should not identify sentence structure with propositional structure

Thomas Hodgson

\section{Constituents and Constituency}

Individuating Fregean sense

Jeff Speaks

The metaphysics of propositional constituency

Lorraine Keller

\section{Theoretical Alternatives to Propositions}

Propositions, attitudinal objects, and the distinction between actions and products

Friederike Moltmann

What are Propositions?

Mark Richard

Conversational implicature, communicative intentions, and content

Ray Buchanan

Propositions and higher-order attitude attributions

Kirk Ludwig

Modal Metaphysics

Unnecessary existents

Joshua Spencer

Contingently existing propositions

Michael Nelson 